Gonçalo Glauco Justino Silva ${ }^{1}$

Mônica Luiza Perin de Souza'

Edward Goulart Júnior ${ }^{2}$

Luiz Carlos Canêo²

Maria Cristina Frollini Lunardelli2

\section{Considerações sobre o transtorno depressivo no trabalho}

\author{
Considerations about depressive disorder at work
}

${ }^{1}$ Licenciados em Psicologia pela Universidade Estadual Paulista, UNESP/ Bauru-SP.

2 Docentes do curso de Psicologia, na área de Psicologia Organizacional e do Trabalho, da Universidade Estadual Paulista, UNESP/Bauru-SP.

Contato:

Edward Goulart Júnior

Avenida Luiz Edmundo Carrijo Coube, 14-01, Vargem Limpa, Bauru, SP. CEP 17033-360.

E-mail:

edward@fc.unesp.br

\section{Resumo}

O presente artigo teve por objetivo tecer considerações sobre os transtornos ou episódios depressivos relacionados ao trabalho, visando fomentar reflexões e facilitar uma maior compreensão sobre a temática. O texto também discorre brevemente sobre algumas condições do contexto de trabalho que podem favorecer o surgimento de episódios depressivos em trabalhadores que estão expostos a tais condições. Para o cumprimento dos objetivos propostos, recorremos à literatura pertinente ao assunto, utilizando, preferencialmente, fontes primárias e secundárias, tanto nacionais quanto internacionais, considerando-se o período de 1984-2008. Consideramos que, à medida que conhecermos melhor as atividades de trabalho, haverá como compreender as vivências subjetivas dos trabalhadores e, dessa forma, surgirão possibilidades mais concretas de torná-las objetivas, facilitando o entendimento da complexa relação saúde mental e trabalho. Essa relação, se tratada de maneira multiprofissional, mostrará que é possível trabalhar sem que isso traga prejuízos para a saúde do homem, dependendo, portanto, da forma e das condições da organização desse trabalho. Cabe às organizações reverem não apenas as condições ambientais e organizacionais disfuncionais do trabalho, mas, sobretudo, seus modelos de gestão, viabilizando práticas que favoreçam a saúde de seus membros.

Palavras-chave: trabalho, depressão, causalidade, transtornos mentais.

\begin{abstract}
This article aims at commenting on depressive episodes or disorders related to work encouraging reflection on the theme and making it easier to understand. In a brief way it discourses about some of the conditions in the work context which may favor the occurence of depressive episodes in workers who experience such conditions. The proposed objectives were achieved by examining the relevant literature and by making use preferably of both national and international primary as well as secondary sources, in the period from 1984 to 2008. We believe that, as soon as we have a better discernment of the work activities, we will be able to understand the workers' subjective experiences. As a result, more concrete possibilities to make them objective will emerge making the complex relationship between mental health and work easier to understand. This relationship, if dealt in a multi-professional manner, will show it is possible to work without harming health. Thus, it relies on the form and the conditions of this work organization. It is part of the organizations duties to review not only the labor dysfunctional environmental and organizational conditions, but also their managerial models, making those practices which promote the health of their workers feasible.
\end{abstract}

Keywords: work, depression, causality, mental disorders.
Recebido: $19 / 05 / 2009$

Aprovado: 28/05/2009 


\section{Introdução}

Vivemos hoje uma realidade de grandes transformações nos processos de trabalho caracterizada, sobretudo, pela rapidez e pelas contínuas e diferentes exigências quanto às novas formas de se trabalhar. Com o advento da tecnologia e da globalização da economia, inúmeros postos de trabalho têm sido extintos e segmentos de trabalhadores são excluídos do sistema formal de produção, promovendo impactos sociais relevantes e desumanização nas relações sociais. Enquanto parte dos excluídos buscam, na economia informal, possibilidades de sobrevivência, outros tantos vivenciam a pauperização, o fenômeno da migração aleatória, na busca pela reinserção profissional.

Para os que se mantêm empregados, sem garantias de permanência, resta à subserviência às metas e aos objetivos organizacionais, flexibilizando-se a todas as necessidades advindas do sistema produtivo em que estão inseridos. Desse modo, são negligenciados em suas necessidades de crescimento e desenvolvimento profissional e, portanto, impossibilitados de concretizarem algum tipo de auto-realização.

Constatam-se exigências cada vez mais severas quanto à qualificação necessária para o trabalho, assim como a intensificação do ritmo de trabalho, a diversificação das atividades e a polivalência funcional como atributo de competência. Em contrapartida, o medo e a apreensão pela demissão a qualquer momento, impedidos de serem expressos, são vivenciados silenciosamente.

Não é difícil suspeitar que "esse novo mundo do trabalho" possa gerar decepções sucessivas e, assim, levar os trabalhadores a transtornos. Dessa forma, faz-se presente uma sobrecarga, principalmente mental, que contamina esse trabalhador em seus aspectos cognitivos e emocionais com consequências psicossociais perversas também para as relações interpessoais.

Kalimo, El Batawi e Cooper (1988), ao reconhecerem a influência dos fatores psicossociais no trabalho e suas relações com a saúde mental, chamam a atenção para a necessidadede que evidenciemos a categoria "trabalho" como objeto de profunda investigação, dando ouvidos à fala dos trabalhadores em seus aspectos de percepção das condições de trabalho e das relações interpessoais entre colegas e superiores.

Esse cenário contemporâneo potencializa a necessidade de se aprofundar estudos sobre o trabalho e suas consequências para a saúde dos trabalhadores, principalmente sobre os transtornos mentais e do comportamento relacionados ao contexto laboral.

O conhecimento produzido, principalmente no Brasil, sobre os transtornos mentais e do comportamento relacionados ao trabalho ainda são insuficientes e inconclusivos para uma compreensão mais aprofundada dessa problemática, configurando-se como um acen- tuado desafio para as organizaçõese, principalmente, para os profissionais da área da saúde, mais especificamente, da saúde ocupacional. Os transtornos mentais estão entre as principais causas de perdas de dias no trabalho, sendo que os transtornos mentais menores (leves) causam em média perda de quatro dias de trabalho/ano e os transtornos mentais maiores (graves), cerca de 200 dias/ano (DEMYTTENAERE et al., 2004).

O trabalho, com todas as suas implicações, pode acarretar ao trabalhador disfunções e lesões biológicas, além de reações psicológicas, desencadeando processos psicopatológicos relacionados às condições em que é desempenhado.

Várias são as condições que podem predispor o trabalhador a situações de sofrimento do trabalho, todas impactando em sua saúde física e mental: fatores relacionados ao ritmo e ao tempo, jornadas longas com poucas pausas, turnos à noite, pressões de chefias por maior produtividade, entre outras.

Uma das principais dificuldades dessa área é o estabelecimento da relação de causalidade entre as doenças e o trabalho, ou seja, correlacionar os transtornos mentais e do comportamento ao trabalho, com toda sua implicação para o homem e para as organizações. Outra dificuldade é identificar as situações laborais que estejam favorecendo o aparecimento e o agravamento dessas doenças.

Ações preventivas dos transtornos mentais e do comportamento relacionados ao trabalho envolvem, necessariamente, um diagnóstico preciso sobre as condições e os ambientes de trabalho, ou seja, o reconhecimento prévio das atividades e dos locais de trabalho onde existam fatores de risco potencial.

O Ministério da Saúde do Brasil e a Organização PanAmericana da Saúde (BRASIL, 2001), de acordo com a Portaria $\mathrm{n}^{\circ} 1.339$, de 18 de novembro de 1999, reconhecem e apresentam lista contendo 12 transtornos mentais e do comportamento relacionados ao trabalho que podem acometer nossos trabalhadores: a) demência em outras doenças específicas classificadas em outros locais; b) delirium, não-sobreposto à demência, como descrita; c) transtorno cognitivo leve; d) transtorno orgânico de personalidade; e) transtorno mental orgânico ou sintomático não especificado; f) alcoolismo crônico; g) episódios depressivos; h) estado de estresse pós-traumático; i) neurastenia; j) outros transtornos neuróticos especificados; k) transtorno do ciclo vigília-sono devido a fatores não orgânicos; l) síndrome de burnout ou síndrome do esgotamento profissional.

Este texto objetiva fomentar reflexões sobre os transtornos ou episódios depressivos relacionados ao trabalho, favorecendo uma maior compreensão dessa temática, considerando que o mundo do trabalho contemporâneo predispõe, cada vez mais, os trabalhadores a condições de risco de natureza psíco-emocional. Propõe-se também discorrer brevemente sobre algumas condições do contexto laboral que podem favorecer o 
surgimento de episódios depressivos em trabalhadores expostos a tais condições.

Para o cumprimento dos objetivos propostos, recorremos à literatura pertinente, utilizando, preferencialmente, fontes documentares primárias (diretas) e secundárias (indiretas), tanto nacionais quanto internacionais, considerando-se o período de 1984-2008.

\section{Considerações sobre o trabalho e a saú- de mental dos trabalhadores}

A palavra trabalho está longe de ter conceito unânime e, de acordo com Codo (1997), ela possui duplo significado em alguns idiomas - aparece como açãoesforço e também como moléstia-fadiga (sofrimento). Para o autor, deve-se compreender o trabalho em comparação com atividade, palavra cujo sentido corrente seria sinônimo de ação, profissão, buscar algo etc. Argumenta, ainda, que atividade, no sentido filosófico, aparece como "qualidade de ser em atos", enquanto a palavra trabalho é freqüentemente usada como sinônimo de atividade, ofício, profissão ou tarefa - de algum modo distinguindo-se de lazer -, configurando-se sempre como resultado de uma ação. No sentido etimológico, então, trabalho está vinculado a um produto, mas atividade, não.

Nessa linha, o autor apresenta a dupla condição do trabalho: enquanto realizador de produtos capazes de atender às necessidades humanas e enquanto relação necessária à sobrevivência no modo de produção atual, no qual o trabalho tem de ser vinculado ao retorno salarial.

Estudos e produções teóricas sobre as transformações no mundo do trabalho são recorrentes e se intensificaram nas últimas décadas. Entretanto, tais buscas explicativas não lograram consenso, uma vez que algumas delas entendem as dimensões do trabalho como mudanças positivas que acompanham as revoluções técnico-científicas e outras enxergam grandes problemas sociais trazidos por tal contexto (LARANJEIRA, 2000).

Borges e Yamamoto (2004) descrevem a evolução do trabalho a partir do surgimento do Capitalismo, conceituando-o como "objeto de múltipla e ambígua atribuição de significados e/ou sentidos”, os quais se relativizam de acordo com os filtros culturais de cada época.

Segundo esses autores, no começo do século XX, a estrutura socioeconômica e política possibilitou condições favoráveis para que se refinassem e se operacionalizassem as formas de gerenciar e organizar o trabalho. Um marco histórico para o tema foi a publicação de Taylor, em 1911, intitulada Princípios da Administração Científica. O taylorismo propagou-se como sistema administrativo que supunha a possibilidade de que patrões e empregados tivessem interesses próximos. Assim, justificava-se o processo de exploração baseado em incentivos salariais aos trabalhadores que assimilassem o desejo de aumentar a produção. $\mathrm{Na}$ mesma época surgiu o fordismo, movimento que consistiu em inovações tecnológicas - concretizadas na linha de montagem, baseada na introdução da esteira rolante na organização da produção - e econômicas -caracterizada pela produção em massa. Datam da época as primeiras preocupações quanto à gestão estratégica de pessoas.

No final da década de 1940, na França, o movimento da "Psiquiatria Social" traz consigo duas grandes correntes: a) a organogênese (sendo Paul Sivadon o seu grande expoente), que compreendia a doença mental de maneira organicista e dinâmica mas, sobretudo, com ênfase nos aspectos orgânicos; e b) a sociogênese (sendo Louis Le Guillant sua figura de destaque), que via a doença mental como uma questão social, olhando para o indivíduo doente no contexto em que ele vive.

Foi Sivadon (1993), da corrente organogênese, que usou pela primeira vez a expressão "Psicopatologia do Trabalho", em 1952, atribuindo a certos tipos de trabalho possibilidades de produzir adoecimento mental nos trabalhadores. Reconheceu também que, dependendo da forma como fosse organizado, o trabalho poderia ser promotor de saúde. Já Le Guillant (1984), da sociogênese, tinha como objetivo defender a predominância dos fatores sociais aos orgânicos na constituição dos distúrbios mentais. Em se tratando da Psicopatologia do Trabalho, estava imbuído da intencionalidade de estabelecer relações entre contextos de trabalho e distúrbios mentais de funcionários que atuavam nesse contexto.

No Brasil, de acordo com o Manual de Procedimentos para os Serviços de Saúde do Ministério do Trabalho e da Organização Pan-Americana da Saúde (BRASIL, 2001, p. 20), com o objetivo de "subsidiar as ações de diagnóstico, tratamento e vigilância em saúde e o estabelecimento da doença com o trabalho e com as condutas decorrentes", foi publicada uma Lista de Doenças Relacionadas ao Trabalho por meio da Portaria/MS n 1.339/1999. A mesma lista passou a ser também usada pelo Ministério da Previdência e Assistência Social (MPAS) com a finalidade de concessão de benefícios relacionados à incapacidade para o trabalho. Corroborou-se, desse modo, a validação do conceito de Doença Profissional e de Doença adquirida pelas condições em que o trabalho é realizado, segundo prescreve o artigo 20 da Lei Federal $n^{\circ} 8.213 / 1991$, constituindo o anexo II do Decreto $\mathrm{n}^{\circ} 3.048 / 1999$.

As medidas legislativas citadas demonstram significativa transformação da atenção dada à saúde dos trabalhadores nos últimos anos. Ainda segundo o manual do Ministério da Saúde (BRASIL, 2001), essa atenção pode ser desenvolvida em diferentes espaços institucionais, ou seja, a responsabilidade é dividida entre Estado, empresas, sindicatos, planos de saúde e serviços especializados de hospitais universitários. Nas organizações, passou a ser obrigatória a criação dos Serviços 
Especializados em Segurança e Medicina do Trabalho (SESMT), os quais enfrentam um sério problema de gestão, pois funcionam quase que exclusivamente sob o comando de empregadores, com pouca ou nenhuma participação do trabalhador.

Assim, no caminho histórico do lidar com o adoecimento laboral, foram realizadas no país, a partir dos anos 1980, uma série de medidas, como a implantação dos Centros de Referência em Saúde do Trabalhador (Cerest), cuja proposta era a criação de locais onde todas as questões sobre doenças do trabalho seriam tratadas, o que possibilitaria vasto armazenamento de informações e produção de conhecimento sobre a temática.

Dados do Ministério da Saúde e da Organização Pan-Americana da Saúde (BRASIL, 2001) apontam que, no começo do século XXI, estavam em funcionamento cerca de 150 programas em todo o país, com ênfase na atenção à saúde de trabalhadores urbanos e com níveis variados de organização, interligando o poder público nas esferas municipal, estadual e federal, além de movimentos sociais e sindicais, o setor privado e sistemas mistos de parceria público-privada. Alguns dos principais méritos desses programas foram o desenvolvimento de práticas e metodologias de vigilância e o estabelecimento de modelos de como preparar profissionais para atendimentos e ações em prol da saúde do trabalhador.

Existem quatro áreas distintas e inter-relacionadas no contexto de trabalho que influenciam na saúde do trabalhador, a saber: as tarefas, as relações interpessoais, as normas e os processos. Para que as tarefas sejam desempenhadas com sucesso, é preciso constante treinamento e especialização como forma de acompanhamento do mercado e das freqüentes mudanças tecnológicas. No entanto, quando esta atualização profissional não acontece, o trabalhador pode sentir insegurança e dependência com relação a colegas e a superiores, podendo gerar acentuada tensão (FIORELLI, 2001).

A carga psíquica do trabalho é outra dimensão do fator "tarefas" a ser considerada, pois se relaciona diretamente com a motivação do empregado. Deve-se atentar para o que o indivíduo quer e pode oferecer para o trabalho a ser desempenhado. Caso haja um desequilíbrio nesses fatores, o ambiente de trabalho pode gerar angústia ao trabalhador, aumento da carga psíquica do trabalho e redução da motivação.

Com relação ao trabalho, Fiorelli (2001) sinaliza que é preciso haver um equilíbrio entre a capacidade física de produção e a quantidade exigida pela organização, visto que seu desequilíbrio pode gerar ansiedade no profissional que não conseguir atingir sua meta. É preciso também haver certa adequação entre o perfil do profissional selecionado para a realização da tarefa e suas exigências.

Agentes nocivos e perturbadores no local de trabalho, como temperaturas elevadas, gases, poeira, barulho etc., também podem levar ao adoecimento do trabalha- dor mesmo que ele não tenha desenvolvido percepção sobre esses fatores.

De acordo com o autor, normas são todo tipo de regras, instruções, política formal ou informal da organização. Há pelo menos dois aspectos relacionados às normas que influenciam diretamente o equilíbrio emocional dos profissionais: a congruência entre os diferentes conteúdos e a sintonia entre as exigências normativas e as características idiossincráticas das pessoas. Aqui, a importância da flexibilidade das normas se faz fundamental, uma vez que instruções paradoxais e o descompasso dessas questões chegam a constituir autêntica tortura emocional.

Albert e Ururahy (1997 apud FIORELLI, 2001) sinalizam para as questões referentes às relações interpessoais como um dos principais fatores causadores de tensão exagerada nas organizações. A inexistência ou insuficiência de treinamento para lidar com colegas ou clientes agressivos, falta de treinamento em expressão verbal, preparo insuficiente de líderes e chefes, falta de informações que originam interpretações equivocadas de motivos que levaram determinado funcionário a agir de uma forma ou de outra, entre outros, podem caracterizar-se como fatores que iniciam ou acentuam conflitos entre as pessoas da organização e, consequentemente, favorecer o adoecimento delas. Conflitos disfuncionais no trabalho atrapalham o bom desempenho dos trabalhadores, desencadeando situações de risco às doenças emocionais. Para Robbins (2005), conflitos oriundos de relações interpessoais são quase sempre disfuncionais; o atrito e a hostilidade interpessoais aumentam o choque de personalidade, reduzindo a compreensão mútua, impedindo ou dificultando as tarefas organizacionais.

Existem também os fatores relacionados aos processos, dos quais podem-se destacar a qualidade e a disponibilidade das informações e o exercício da autoridade. Falhas relacionadas aos processos enviesam o trabalho, geram conflito entre as pessoas e aumentam a ansiedade do trabalhador - que passa a sofrer por antecipação.

Os estilos de liderança também representam um importante influenciador do ambiente de trabalho, podendo se configurar pelo autoritarismo e por acentuada centralização de poder, estilo que pode levar à diminuição da motivação, ao descontentamento e ao baixo grau de integração, elementos diretamente ligados à ansiedade, a comportamentos problemáticos, à depressão, entre outros. A liderança também pode se manifestar de modo a gerar segurança e certa autonomia, assim como o fortalecimento de emoções positivas, com sensações de pertencimento, diminuindo a ansiedade e configurando um quadro propício para a busca e a aquisição de habilidades e, nesse sentido, a liderança democrática/ participativa tem claramente melhor espectro de conseqüências positivas em relação à autocrática.

É importante ressaltar também a diferença entre motivação e satisfação no trabalho. Enquanto a primeira é um elemento intrínseco, ligado ao significa- 
do e ao caráter do trabalho em si realizado, a última é extrínseca, ligada a aspectos como salário, benefícios, reconhecimento, liderança, relacionamento interpessoal, dentre outras condições presentes no ambiente de trabalho. Esses últimos são os elementos formadores do clima organizacional, o qual reflete uma estimativa dos níveis de satisfação da organização e das pessoas integrantes (CODA, 1997).

A motivação no trabalho é estudada por diversos autores, resultando em diferentes teorias para o fenômeno. Cury (2005) fala sobre uma delas - a teoria bifatorial, proposta por Herzberg -, a qual estabelece duas classes representativas de fatores influenciadores da motivação ocupacional. Os fatores higiênicos estariam relacionados ao contexto organizacional, como salário, benefícios, condições de trabalho, relacionamento interpessoal. Os fatores relacionados ao conteúdo, ao significado e ao reconhecimento do trabalho representam os fatores motivacionais. Dessa forma, a motivação é vista como dependente da relação indivíduo-grupo, considerando a subjetividade e a singularidade, assim como a cultura e o contexto.

As organizações possuem uma cultura própria, com valores, crenças, símbolos, histórias, normas que permeiam, influenciam e/ou determinam o seu funcionamento e, para sua sobrevivência no mercado atual, elas devem ser capazes de trocar relações com o ambiente externo e modificarem-se, buscando adaptação às demandas presentes.

Limongi-França e Rodrigues (1999) apontam que a ambigüidade e a incompatibilidade de papéis são fatores que podem representar estressores psicossociais no ambiente de trabalho. Como conseqüência, poderiam aparecer a insatisfação no trabalho, prejuízo no vínculo em relação às tarefas, redução da confiança na organização, motivação prejudicada, tendência ao abandono do emprego, maior incidência de problemas de ordem psicológico-emocional e fenômenos psicossomáticos.

Indicadores como prazer, satisfação, bem-estar, sofrimento e burnout (tipo de acometimento de estresse específico de condições do trabalho) constituem elementos da psicodinâmica do trabalhador, estudados sob a ótica de diferentes abordagens, como a Medicina do Trabalho, a Psicologia Social e a Psicologia Organizacional e do Trabalho (MENDES; CRUZ, 2004).

Iório (2006) levanta alguns elementos predisponentes do ambiente corporativo para os transtornos mentais, em especial a depressão. Destacam-se, assim, os fatores correlacionados ao funcionamento da instituição, como valorização e exigência de ações de controle, altas cobranças por resultados e produtividade, medo de desligamento arbitrário e imediato e, finalmente, submissão às conseqüências de uma cultura organizacional comprometida. Para o autor, esse contexto complexo de fenômenos gera diversas necessidades sócioorganizacionais, entre elas a crescente demanda pela presença de profissionais de saúde nas organizações, os quais ainda se deparam com dificuldades, como baixos recursos voltados à promoção da saúde mental, além de diagnósticos e encaminhamentos precoces. Sendo assim, o estado emocional do trabalhador comprome te-se gradualmente.

As relações interpessoais intra-organizarão podem gerar também a supressão da manifestação emocional do trabalhador, diminuição de atitudes espontâneas, exposição ao risco dos efeitos colaterais negativos da competitividade, embotamento afetivo e funcionamento grupal disfuncional e conflituoso (GONDIM; SIQUEIRA, 2004).

A conjuntura econômica interna e a externa também representam uma variável influente e significativa, como, por exemplo, a suscetibilidade da unidade organizacional à instabilidade macroeconômica. Muitas vezes, observa-se a lógica de baixar custos, na qual não prevalece o interesse em desenvolver práticas cooperativas e mantenedoras do ambiente saudável no cotidiano corporativo (IÓRIO, 2006).

\section{Compreendendo o transtorno depressivo}

Kaplan, Sadock e Grebb (1997) entendem o humor como o estado emocional interno mais constante do indivíduo e o afeto como a expressão externa do conteúdo emocional atual. Nessa linha, para os autores, a depressão estaria enquadrada como um transtorno de humor. Os principais transtornos de humor são o transtorno distímico, o transtorno depressivo maior, o transtorno ciclotímico e o transtorno bipolar I. No Compêndio de Psiquiatria (1997), obra elaborada pelos autores, encontra-se o posicionamento da quarta edição do Diagnóstico Estatístico de Transtornos Mentais (DSM-IV) sobre outras categorias de transtornos de humor que ainda podem ser diagnosticadas, tais como depressivo menor, depressivo breve recorrente, transtorno disfórico pré-menstrual, transtorno de humor devido a uma condição médica geral e transtorno de humor induzido por substância.

O transtorno depressivo menor pode ser detectado pelos mesmos critérios diagnósticos do transtorno depressivo maior, mantendo-se a duração da sintomatologia, porém com graus de severidade acentuadamente menores. Já no transtorno depressivo breve recorrente ocorre ao contrário, ou seja, os sintomas depressivos satisfazem o critério para transtorno depressivo maior em termos de severidade, mas não em duração. O transtorno depressivo menor e o transtorno depressivo breve recorrente diferem-se do transtorno distímico na medida em que este é um transtorno depressivo crônico e não caracterizado por episódios distintos, enquanto aqueles apresentam episódios delimitados. O transtorno disfórico pré-menstrual envolve sintomas do humor, comportamentais e físicos em determinado período do ciclo menstrual (KAPLAN; SADOCK; GREBB, 1997).

Os critérios diagnósticos para o transtorno depressivo maior, de acordo com o DSM-VI e extraídos 
do Compêndio de Psiquiatria (KAPLAN; SADOCK; GREBB, 1997) são: (a) presença de cinco (ou mais) dos seguintes sintomas: humor deprimido; interesse ou prazer acentuadamente diminuídos por todas ou quase todas as atividades; perda ou ganho significativo de peso quando não está realizando dieta ou diminuição ou aumento no apetite; insônia ou hipersonia; agitação ou retardo psicomotor; fadiga ou perda de energia; sensação de inutilidade ou culpa excessiva ou inapropriada; capacidade diminuída para pensar ou concentrar-se, ou indecisão; (b) pensamentos recorrentes sobre morte, ideação ou tentativas de suicídio; (c) os sintomas causam sofrimento clinicamente significativo ou comprometimento no funcionamento social, ocupacional ou em outras áreas importantes da vida do indivíduo; (d) os sintomas não são devido aos efeitos fisiológicos diretos de uma substância ou uma condição médica geral; (e) os sintomas não são melhor explicados por Luto. Os autores destacam que o transtorno depressivo maior, trazido no DSM-IV, veio substituir a depressão maior, descrita no DSM-III-R (terceira edição revisada do Diagnóstico Estatístico de Transtornos Mentais) em função do acréscimo de critérios ligados ao comprometimento no funcionamento social e ocupacional.

Estes sintomas podem aparecer como episódios de tristeza vivenciados em certos momentos da vida. Somente quando se acentuam significativamente em frequência e intensidade, aparecendo em conjunto, é que o transtorno depressivo maior é caracterizado. O quadro sintomatológico para este transtorno configura-se como uma tristeza de maior intensidade e frequência que uma tristeza cotidiana comum. Indivíduos acometidos com o transtorno apresentam baixa responsividade em relação aos elementos do meio, incluindo o trabalho, com sintomas como redução no nível de motivação, retardo psicomotor, lentidão do pensamento, pessimismo extremo, baixa auto-estima e sentimentos de desvalorização. Aparecem também pensamentos intrusivos, idealizações suicidas, sintomas e manifestações de ordem somática, além de alterações e perturbações como perda de apetite, alterações do ciclo de sono-vigília e perda do interesse sexual. Entretanto, ressalta-se que é preciso uma alteração significativa na frequência e na intensidade desses elementos para caracterizar-se a depressão.

No texto, o termo "depressão" será utilizado para se referir ao transtorno depressivo maior, bastante frequente nos dias atuais, considerado epidêmico por alguns estudiosos da área. Kaplan, Sadock e Grebb (1997) classificam o transtorno depressivo maior em três níveis: (a) leve, com pequeno comprometimento no funcionamento ocupacional, de atividades sociais habituais ou de relacionamento interpessoal; (b) moderado, de acometimento intermediário às outras formas; (c) severo, com aspectos psicóticos como delírios ou alucinações.
O transtorno depressivo maior, de acordo com o DSM-IV e a Classificação Internacional de Doenças (CID-10), é um transtorno comum e com prevalência de manifestação no sexo feminino, porém com desconhecimento causal para tal afirmação. Chama-se a atenção que tal apontamento pode estar, de certa forma, enviesado pelo modo de organização da sociedade e suas "exigências" culturais, ocasionando um sentimento de "necessidade de conter as emoções" pelo sexo masculino e do oposto pelo feminino.

Uma das maiores dificuldades para o enfrentamento dessa patologia é sua característica de retroalimentação, isto é, os sintomas que acometem as pessoas as impedem de desenvolver e executar ações que poderiam auxiliá-las a sair do quadro. Sendo assim, a retroalimentação leva o indivíduo a não ter comportamentos socialmente significativos, tais como o estabelecimento de bons relacionamentos interpessoais, trocas afetivas, atividades em grupo (profissionais ou não), novas condições de trabalho etc., agravando ainda mais os sintomas depressivos. Assim, muito da manutenção do quadro depressivo deve-se ao grande período em que o indivíduo se imerge em um estado letárgico, que inclui pensamentos negativos sobre si próprio, os outros e o ambiente de uma forma geral.

As manifestações do transtorno depressivo maior têm sido, em geral, alvo de interesse para diversos enfoques da Psicologia e ciências afins. O interesse se encontra na manifestação deste transtorno em suas relações com o ambiente de trabalho, como objeto de estudo para a Psicologia Organizacional e do Trabalho, enquanto área que visa à prevenção e à promoção de saúde mental, à produção de conhecimento científico e à funcionalidade do trabalho multiprofissional.

\section{Transtorno depressivo no trabalho}

Os trabalhadores, de modo geral, são submetidos a uma série de fatores de risco ocupacionais. Rocha (2003 apud MENDES; CRUZ, 2004) destaca que frustrações e experiências angustiantes vividas no trabalho podem desencadear, dentre outros, sintomas depressivos. Com base no referencial teórico da Psicodinâmica do Trabalho de Dejours (1992), aponta-se que quadros de depressão ocupacional tendem a estar associados com a percepção do trabalhador de que ele não tem o reconhecimento de pessoas ou grupos que integram suas relações sócio-profissionais, fenômeno que gera ambiguidade psicológica, pois o trabalho não se mostra mais como possibilidade de realizar seus desejos e de ser referendado por colegas e superiores.

No intuito de aprofundar os vieses e especificidades da identificação da depressão com nexo causal na atividade laboral, cabe investigar a questão partindo de elementos circunscritos ao cotidiano do ambiente do trabalho. Estudos realizados por Gondim e Siqueira (2004 apud MENDES; CRUZ, 2004), entre 1996 e 2001, 
apontam que apenas 5\% de 200 artigos científicos encontrados em periódicos sobre comportamento organizacional enfocavam a análise do prazer e sofrimento psicológicos relacionados à atividade laboral.

O Manual de Procedimentos para os Serviços de Saúde do Ministério da Saúde e da Organização Pan-Americana da Saúde (BRASIL, 2001) aponta "fatores de risco de natureza ocupacional conhecida” para a depressão. Entre eles aparecem decepções sucessivas em situações de trabalho frustrantes, as perdas acumuladas ao longo de anos de trabalho, perda do posto de trabalho e demissão. Aponta, a partir de estudos comparativos, maior incidência de depressão em digitadores, operadores de computadores, advogados, educadores especiais e consultores. Entretanto, alguns episódios depressivos estão associados à exposição ocupacional a certas substâncias químicas, como os solventes orgânicos neurotóxicos.

A depressão ocupacional atesta a ineficácia das possíveis mediações utilizadas pelo trabalhador para se conservar saudável e afugentar o adoecimento no trabalho. Isso se dá por tais mediações dependerem mais das condições objetivas de trabalho do que de características individuais do perfil psicológico de cada trabalhador. Essas condições, portanto, impossibilitam, muitas vezes, a subjetivação dos indivíduos e do coletivo, a realização profissional, o desenvolvimento da identidade, podendo gerar frustração e a presença da depressão ocupacional (MENDES; CRUZ, 2004).

A depressão está usualmente ligada ao estresse, ao esgotamento e à falta de prazer e satisfação no exercício profissional, articulada à repetição contínua seguida de mal-estar e apatia para desenvolver estratégias de enfrentamento dessa adversidade. A cristalização desse processo conduz à denominação classificatória de doença ocupacional. Enquanto doença ocupacional, a delimitação do quadro depressivo ainda pode subdividir-se em situacional e estrutural (MENDES; CRUZ, 2004). Por meio da investigação científica caso a caso, pode-se distinguir os subtipos, condicionando o diagnóstico ao fato do trabalho ter atuado como colaborador ou desencadeador do quadro depressivo. No primeiro, a atividade laboral "meramente" contribuiria com a formulação patológica. Já no segundo, o próprio trabalho "desata o nó" para a manifestação dos sintomas depressivos no trabalhador. Ademais, em ambos os casos, a depressão manifesta-se por meio de seus sintomas típicos supracitados.

O "controle" detido pelo trabalhador acerca de seu estado emocional é o principal diferencial para que se faça a distinção diagnóstica entre um estado mais grave ou mais leve de depressão. No âmbito do trabalho, a depressão situacional tem por característica marcante a transitoriedade dos sintomas, bem como a aptidão que o trabalhador desenvolve para confrontar e eventualmente superar o estado depressivo, sendo considerada, portanto, leve. Na contramão dessa possível superação, o quadro grave, típico da depressão estrutural, está atrelado à perda de controle sobre si, vivenciada pelo trabalhador. O quadro se intensifica devido a sérios comprometimen- tos na integridade física, psíquica e social do sujeito gravemente deprimido (MENDES; CRUZ, 2004).

A estimativa norte-americana, de acordo com Timms (2006), revela que $30 \%$ dos trabalhadores terão algum acometimento em saúde mental a cada ano, sendo a depressão um dos mais comuns. O autor sinaliza que o adoecimento mental desencadeia comprometimento do rendimento no trabalho, ocasionando elevação do quadro de absenteísmo por doença, acidentes de trabalho e rotatividade de pessoal. O empregado acometido por depressão poderá apresentar, segundo o autor, elevada taxa de erros nas tarefas, dificuldade de concentração, incapacidade de delegar tarefas, lentidão, execução das atividades com intenso sofrimento psíquico, atrasos em compromissos, entre outros.

A Organização Mundial da Saúde (HARNOIS, 1996) sinaliza a depressão como a principal causa de perda de trabalho no mundo, projetando que, antes do ano de 2020, ela aparecerá como a principal causa da incapacitação de trabalhadores para o trabalho.

Ressalta-se a relevância da necessidade de ajuda de outrem para que o indivíduo enfrente o quadro depressivo em seu estado mais grave. Nessas ocasiões, é preciso que profissionais especializados estejam preparados para realizar a devida leitura psíquica do indivíduo que sofre desse mal, atentando para possíveis sinalizadores típicos de outros transtornos, tais como manifestações de pânico e fobias resistentes a mudanças no contexto de trabalho - e que por isso demandam intervenções específicas para sua remoção.

O tratamento e outras condutas para a depressão, de acordo com o Manual de Procedimentos para os Serviços de Saúde do Ministério da Saúde e da Organização PanAmericana da Saúde (BRASIL, 2001), depende da gravidade e da especificidade de cada caso, podendo envolver psicoterapia, tratamento farmacológico, dependendo da gravidade do caso, e intervenções psicossociais. Como prevenção, propõe a vigilância dos ambientes, das condições de trabalho e dos efeitos ou danos à saúde do trabalhador. Para tal, requer ação integrada e articulada entre os setores de trabalho, com suporte de equipe multiprofissional e interdisciplinar. Essas equipes devem estar capacitadas para o trato e o suporte ao sofrimento psíquico, aos aspectos sociais e para intervenção no ambiente de trabalho.

\section{Considerações finais}

Abordar o tema saúde/adoecimento mental no ambiente de trabalho envolve diversas nuances, como interesses e pontos de vista nem sempre convergentes. O estabelecimento de uma causalidade entre esses fatores também é uma questão polêmica e envolve aspectos éticos, política previdenciária e burocracia intersetorial. Nesse sentido, Glina et al. (2001) apontam o estabelecimento de nexo causal entre adoecimento e situação de trabalho como uma questão complexa, visto que isso 
envolve idiossincrasias e características individuais, assim como história de vida e de trabalho enquanto fatores influenciadores, configurando-se um processo específico para cada indivíduo. Os autores defendem ser fundamental para o nexo causal entre o agravo que acomete o trabalhador e o trabalho a descrição detalhada da situação de trabalho, envolvendo o ambiente, $a$ organização e a percepção da influência do trabalho no processo de adoecer.

Diante das explanações teóricas até aqui descritas, com importantes estudiosos do tema, resta-nos a intenção de tecer algumas considerações que possam expressar nosso posicionamento frente à questão até então tratada.

Inicialmente, é de fundamental importância que os profissionais da área da Saúde Mental e Trabalho resgatem, de fato, o trabalho como categoria transversal imprescindível na vida humana para poder compreender o homem em sua complexa rede de relacionamentos entre a subjetividade e a objetividade. Afastar-se da tendência de privilegiar quaisquer dessas dimensões para efeito de análise é outra atitude necessária.

Foram os trabalhos de Guillant que trouxeram à tona a questão da relação entre subjetividade e objetividade que, acreditamos, até hoje, melhor sustentam a relação sujeito/objeto. Para ele, a experiência vivida pelos trabalhadores não deveria ser desconsiderada e, por mais subjetiva que fosse, haveria nela embutida dimensões da realidade que os trabalhadores teriam condições de resgatar.

Sendo assim, é possível, por meio da análise e da compreensão das condições de vida e de trabalho dos trabalhadores (dimensões objetivas) e do resgate da história vivida (dimensões subjetivas), trazer à tona as questões do homem no seu contexto de trabalho, abordagem essa que ele chamou de "pluridimensional" por permitir um trânsito de uma dimensão para outra.

O resgate das situações concretas de trabalho pode ser feito pela Análise Ergonômica do Trabalho (para compreender o espaço real do trabalho) e pela Psicossociologia do Trabalho (para compreender a subjetividade dos trabalhadores), enquanto disciplinas que podem auxiliar no processo de compreensão das experiências subjetivas, intersubjetivas e objetivas dos trabalhadores.

Para o processo de angariar informações, pode-se utilizar todos os instrumentos disponíveis, tais como ques-

\section{Referências}

BORGES, L. O.; YAMAMOTO, O. H. O mundo do trabalho. In: ZANELLI, J. C; BORGES-ANDRADE, J. E.; BASTOS, A. V. B. (Org.). Psicologia, organizações e trabalho no Brasil. Porto Alegre: Artmed, 2004. p. 24-62.

BRASIL. Ministério da Saúde do Brasil; Organização Pan-Americana da Saúde. Doenças relacionadas ao tionários, entrevistas, observações, além de consultas ao ambulatório médico da organização, dados estatísticos existentes na literatura, contato com sindicatos da categoria, órgãos que cuidam da saúde do trabalhador etc.

À medida que tivermos um profundo entendimento da atividade de trabalho, haverá como compreender as vivências subjetivas dos trabalhadores e, dessa forma, surgirão possibilidades mais concretas de torná-las objetivas. Com isso, será possível entender as imbricadas relações entre saúde mental e trabalho que, se tratadas de maneira multiprofissional, mostrarão que é possível trabalhar sem que isso traga prejuízos para a saúde do homem, dependendo, portanto, da forma e das condições de organização do trabalho.

A importância da atuação de profissionais da saúde no combate e na prevenção do adoecimento psíquico nas organizações é muito grande, principalmente em atividades de diagnóstico organizacional e em programas de intervenção que venham ao encontro da manutenção de um clima positivo de trabalho, favorecendo a saúde dos trabalhadores. Outra questão relevante é dar atenção especial às incompatibilidades entre os requisitos técnicos e humanos exigidos para o esperado desempenho nos cargos e as características apresentadas pelos indivíduos. Para tal, processos seletivos bem planejados e conduzidos, assim como práticas de gestão do desempenho, são condições essenciais. O desenvolvimento de programas de Treinamento e Desenvolvimento (T\&D), visando à capacitação e ao aprimoramento pessoal e profissional dos trabalhadores, configura-se também como uma prática importante na busca do equilíbrio entre exigências do trabalho e a capacidade dos profissionais para atendê-las. Nessas práticas de gestão de pessoas, devem estar envolvidas equipes multiprofissionais e especialistas ligados às áreas da saúde, técnicas e administrativas.

Cabe às organizações reverem não apenas as condições ambientais e organizacionais disfuncionais do trabalho, mas, sobretudo, seus modelos de gestão da saúde para o trabalhador. As organizações devem viabilizar práticas que favoreçam a saúde de seus membros, visto que iniciativas dessa natureza são economicamente mais interessantes do que a remediação dos efeitos de eventuais transtornos mentais que possam afligi-los. Ao agirem dessa forma, as empresas irão se mostrar social e eticamente comprometidas com a integridade física e mental de seus trabalhadores.

trabalho: manual de procedimentos para os serviços de saúde. Brasília: Ministério da Saúde, 2001. (Série A. Normas e manuais técnicos, n. 114)

CODA, R. Pesquisa de clima oganizacional e gestão estratégica de recursos humanos. In: BERGAMINI, C. W.; CODA, R. (Org.). Psicodinâmica da vida 
organizacional: motivação e liderança. São Paulo: Atlas, 1997. p. 94-107.

CODO, W. Um diagnóstico do trabalho (em busca do prazer). In: TAMAYO, A.; BORGES-ANDRADE, J. E.; CODO, W. (Org.). Trabalho, organizações e cultura. São Paulo: Cooperativa de Autores Associados, 1997. p. 21-40.

CURY, A. Organização e métodos: uma visão holística. 8. ed. rev. e ampl. São Paulo: Atlas, 2005.

DEJOURS, C. A Loucura do trabalho: estudos sobre a psicopatologia do trabalho. 5. ed. ampl. São Paulo: Cortez-Oboré, 1992.

DEMYTTENAERE, K. et. al. Prevalence, severity, and unmet need for treatment of mental disorders in the World Health Organization World Mental Health Surveys. JAMA: The Journal of the American Medical Association, United States, v. 291, n. 21, p. 2581-2590, June 2004

FIORELLI, J. O. Psicologia para administradores: integrando teoria e prática. 2. ed. São Paulo: Atlas, 2001.

GLINA, D. M. R. et al. Saúde mental e trabalho: uma reflexão sobre o nexo com o trabalho e o diagnóstico, com base na prática. Cadernos de Saúde Pública, Rio de Janeiro, v. 17, n. 3, p. 607-616, maio/jun. 2001.

GONDIM, S. M. G.; SIQUEIRA, M. M. M. Emoções e afetos no trabalho. In: ZANELLI, J. C.; BORGESANDRADE, J. E.; BASTOS, A.V.B. (Org.). Psicologia, organizações e trabalho no Brasil. Porto Alegre: Artmed, 2004. p. 207-236.

HARNOIS, G. P. Formulation of mental health policy. In: WORLD HEALTH ORGANIZATION. Global action for the improvement of mental health care: policies and strategies. Geneva: WHO/MNH/MND/96.4, 1996. p. 21-27.

IÓRIO, A. L. Saúde mental em ambiente corporativo. São Paulo: Empregos.com.br - comunidade RH, 2006. Disponível em: <http://carreiras.empregos.com. br/comunidades/rh/artigos/170204-saude_depresao andre.shtm>. Acesso em: 14 jun. 2008.

KALIMO, R.; EL BATAWI, M. A.; COOPER, C. L. Los fatores psicosociales em el trabajo y su relación com la salud. Ginebra: Organización Mundial de la Salud, 1988.

KAPLAN, H. I.; SADOCK, B. J.; GREBB, J. A. Transtornos de Humor. In: Compêndio de psiquiatria: ciências do comportamento e psiquiatria clínica. 7. ed. Porto Alegre: Artmed, 1997. p. 493-544.

LARANJEIRA, S. M. G. As transformações do trabalho num mundo globalizado. Sociologias, Porto Alegre, ano 2, n. 4, p. 14-19, jul./dez. 2000. Disponível em: <http://www.scielo.br/pdf/soc/n4/socn4a02.pdf>. Acesso em: 14 jun. 2008.

LE GUILLAND, L. (Org). Quelle psychiatrie pour notre temps? Travaux et écrits de Louis Le Guillant. Toulouse: Erès, 1984.

LIMONGI-FRANÇA, A. C.; RODRIGUES, A. L. Stress e trabalho: uma abordagem psicossomática. 2. ed. São Paulo: Atlas, 1999.

MENDES, A. M.; CRUZ, R. M. Trabalho e saúde no contexto organizacional: vicissitudes teóricas. In: TAMAYO, A. et al. Cultura e saúde nas organizações. Porto Alegre: Artmed, 2004. p. 39-55.

ROBBINS, S. P. Comportamento organizacional. São Paulo: Pearson Prentice Hall, 2005.

SIVADON, P. Psychiatries et socialites: récit autobiographique et réflexions théoriques d'un psyquiatre français. Toulouse: Erès, 1993.

TIMMS, P. Depression in the workplace. The Royal College of Psychiatrists, 2006. Disponível em: <http:// www.rcpsych.ac.uk/mentalhealthinformation/ mentalhealthproblems/depression/ depressionintheworkplace.aspx>. Acesso em: 14 jun. 2008. 